\title{
Cutaneous lymphangioma circumscriptum after mastectomy for breast cancer
}

\author{
Anissa Zaouak', Wafa Koubaa², Houda Hammami ${ }^{3}$, Samy Fenniche ${ }^{4}$ \\ ${ }^{1}$ Dermatology Department, Habib Thameur Hospital, Tunis, Tunisia, ${ }^{2}$ Anatomopathology Department, Habib Thameur \\ Hospital, Tunis, Tunisia
}

Corresponding author: Dr. Anissa Zaouak, E-mail: anissa_zaouak@yahoo.fr

Sir,

Lymphangioma circumscriptum (LC) is a superficial cutaneous cystic malformation secondary to abnormalities of lymphatic development [1]. LC is a rare benign tumor, and so are cutaneous lymphangiomas, accounting for $4 \%$ of all vascular tumors [1]. LC is usually congenital but may appear later. Acquired $\mathrm{LC}$ is reported to occur from trauma, as from surgery, radiotherapy, or the combination thereof [2]. Herein, we report a case of cutaneous lymphangioma complicating the radiosurgical treatment of breast cancer. A 42-yearold female, with a history of vitiligo persistent for ten years prior, was diagnosed with carcinoma of the left breast in 2017. She underwent a mastectomy of the left breast with axillary lymph node clearance followed by chemotherapy and radiotherapy. The patient presented herself to our department of dermatology with multiple vesicles on the left axillary fold evolving for the last two months. A dermatological examination revealed multiple small skin-colored vesicles on the left axillary fold (Fig. la), which were neither itchy nor painful. A dermoscopic examination revealed lacunas of brownorange discoloration associated with fine linear vessels (Fig. 1b). A biopsy revealed lymphatic ducts with thin walls in the papillary dermis and with erythrocytes in the lumens of lymphatic vessels (Fig. 2). Based upon all clinical, dermoscopic, and histological findings, a diagnosis of lymphangioma circumscriptum was given. The patient was treated with surgical excision with excellent results. There was no recurrence within a one-year follow-up period.

Cutaneous lymphangioma circumscriptum (CL), also known as a superficial lymphatic malformation, is a rare benign tumor and the most common kind of lymphangioma [1]. CL may compromise any cutaneous or mucosal surface, but mainly the neck, axilla, breast, chest, buttocks, thighs, and oral mucosa [2]. CLC is frequently observed in females and is clinically characterized by the presence of multiple translucent small vesicles, either isolated or confluent. Dermoscopy is useful for diagnosis of CL, showing multicoloredwhite, yellow, brown, orange-lacunae in addition to vascular structures [3]. Histology confirms the diagnosis suspected clinically and dermoscopically, showing lymphatic ducts in the papillary dermis with thin walls and sometimes with erythrocytes in the lumens of lymphatic vessels [4]. Although dermoscopy is a tool for the rapid diagnosis of CLC, histology remains the gold standard for the definitive [5]. The differential diagnosis of CL may include herpes zoster, hemangiomas, angiokeratomas, viral warts, molluscum contagiosum, and epidermal nevi $[1,2]$. Surgical excision, as performed in our patient, is the preferred approach producing low rates of recurrence $[1,4]$. Other treatment options may include cryosurgery, electrodessication, ablative CO2 laser therapy, and radiotherapy. Because a recurrence may develop after treatment, close follow-ups are recommended. Lymphangiomas may be localized or generalized, and may be congenital or acquired, as in our case [1].

In fact, the CLC in our patient appeared after radiotherapy for breast cancer. Radiotherapy can lead to tissue complications. Lesions caused by radiotherapy occur mainly at the junction of the reticular dermis and adipose tissue, resulting in fibrosis, lymphatic obstruction, increased local pressure, and, consequently, lymphatic fluid accumulation. Clinically,

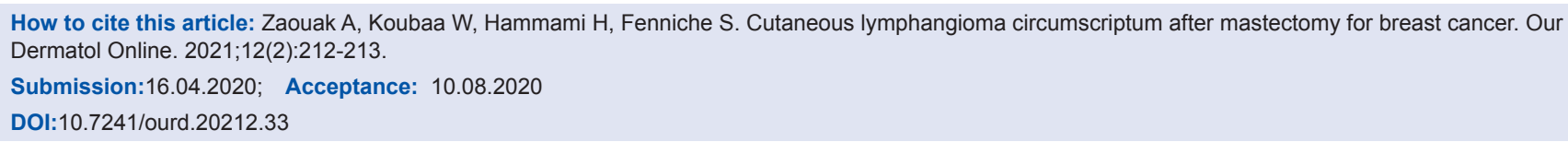




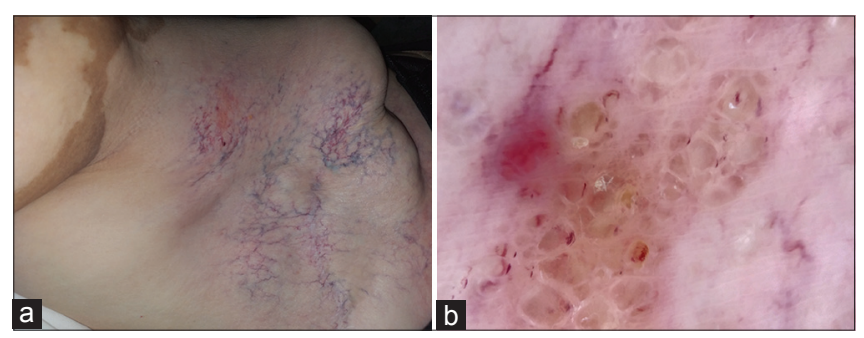

Figure 1: (a) Multiple translucent small vesicles on the left axillary fold. (b) Dermoscopy showing lacunas of brown-orange discoloration with fine linear vessels.

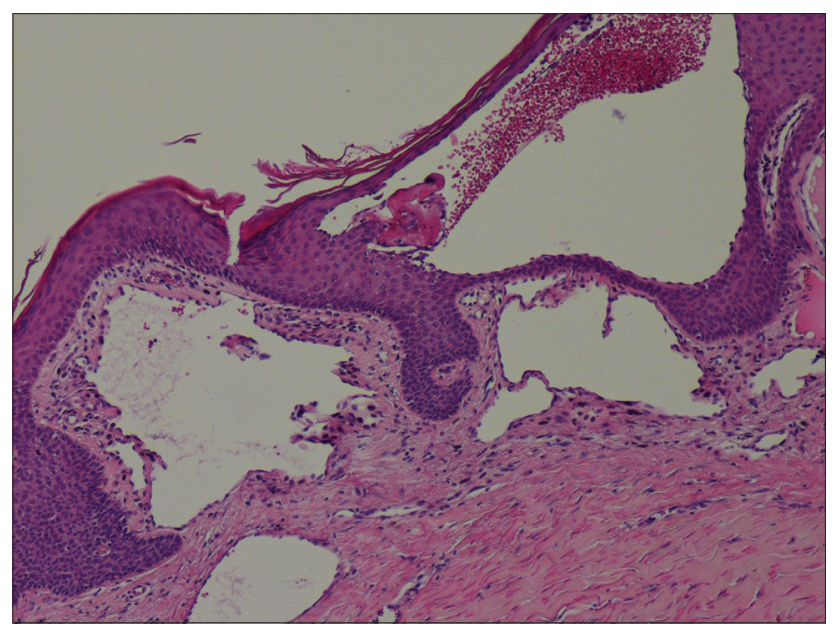

Figure 2: Lymphatic ducts with thin walls in the papillary dermis and with erythrocytes in the lumens of lymphatic vessels (H\&E, 100x).

due to saccular dilatation of the superficial lymphatic channels, lesions may vary from vesicles to reddish nodules [2].

In summary, CLC is a rare benign cutaneous neoplasm, and clinicians should be aware of the probability of its appearance after radiotherapy for breast cancer.

\section{ACKNOWLEDGEMENTS}

We would like to thank the patient.

\section{Consent}

The examination of the patient was conducted according to the principles of the Declaration of Helsinki.

The authors certify that they have obtained all appropriate patient consent forms, in which the patients gave their consent for images and other clinical information to be included in the journal. The patients understand that their names and initials will not be published and due effort will be made to conceal their identity, but that anonymity cannot be guaranteed.

\section{REFERENCES}

1. Patel GA, Schwartz RA. Cutaneous lymphangioma circumscriptum: frog spawn on the skin. Int J Dermatol. 2009;48:1290-5.

2. Chee JN, Koh MJ. Vesicles on the breast post-mastectomy: a quiz -lymphangioma circumscriptum. Acta Derm Venereol. 2015;95:1037-9.

3. Zaballos P, Del Pozo LJ, Argenziano G, Karaarslan IK, Landi C, Vera A, et al. Dermoscopy of lymphangioma circumscriptum: A morphological study of 45 cases. Australas J Dermatol. 2018;59:e189-93.

4. Gomides MDA, Costa LD, Berbert ALCV, Janones RS. Cutaneous lymphangioma circumscriptum: The relevance of clinical, dermoscopic, radiological, and histological assessments. Clin Case Rep. 2019;7:612-5.

5. Massa AF, Menezes N, Baptista A, Moreira AI, Ferreira EO. Cutaneous Lymphangioma circumscriptum - dermoscopic features. An Bras Dermatol. 2015;90:262-4.

Copyright by Anissa Zaouak, et al. This is an open access article distributed under the terms of the Creative Commons Attribution License, which permits unrestricted use, distribution, and reproduction in any medium, provided the original author and source are credited. Source of Support: Nil, Conflict of Interest: None declared. 